\section{University of New Hampshire}

Carsey School of Public Policy

\section{CARSEY}

National Fact Sheet \#27
RESEARCH

Winter 2014

\title{
New Population Projections Reflect Slower Growth and Increasing Diversity
}

Kenneth M. Johnson

$\mathrm{T}$ wo important demographic trends are reflected in newly released Census Bureau projections. The pace of U.S. population growth is slowing, and the population continues to become more diverse. These trends reflect distinctly different demographic trajectories among whites and minorities driven by the interaction of several key demographic forces. This will produce a rich tapestry of demographic change in the United States over the next several decades.

Non-Hispanic whites currently represent 63 percent of the population and are projected to remain in the majority until the mid-2040s. This white population is barely growing, and projections released today indicate it will begin to decline between 2025 and 2030. Growth is slow because the non-Hispanic white population is aging, which reduces fertility and increases mortality.

Currently, whites account for 79 percent of all deaths, but only 50 percent of births. In each of the last two years, more non-Hispanic whites died than were born. Such natural decrease is without precedent in U.S. history. It was not expected to begin until the 2020s, when deaths among large cohorts of aging baby boomers were projected to exceed births to the diminishing number of young non-Hispanic whites of childbearing age.

The sharp decline in fertility associated with the Great Recession has, however, accelerated this trend. With no natural increase and modest immigration, the non-Hispanic white population has grown by just 516,000 (.3 percent) since 2010. Though non-Hispanic white natural increase may occur again as fertility rates recover from the economic downturn, it is likely to be short-lived. Projections released today suggest consistent natural decrease by the 2020s and a minimal white population increase until the 2030s, via immigration, followed by accelerating population losses. Ironically,

\section{KEY FINDINGS}

Non-Hispanic white population growth is minimal and projected to remain so.

Minority population growth is projected to be significant.

The excess of births over deaths, not immigration, will produce most of the growth.

Children are in the vanguard of a population that is becoming more diverse from youngest to oldest.

Non-Hispanic whites have been more dependent on immigration for population increase than any other group since 2010.

since 2010, non-Hispanic whites have been more dependent on immigration for population increase than any other group. The new projections indicate that this trend will continue.

Minority populations already account for almost all of the nation's population increase, and the new projections suggest this will continue. Since 2010, nearly 93 percent of the U.S. population gain of 7.4 million came from minorities. Hispanics caused nearly half of this gain. The new projections indicate that, by 2030, minority populations will account for all U.S. population increase and offset population declines among non-Hispanic whites. By 2045, the new projections suggest the majority of the population will be from groups other than non-Hispanic whites. By 2060, nearly 29 percent of the population will be Hispanic compared to 18 percent today (see Figure 1). African Americans and Asians are projected to be a growing but still modest share of the population in coming years.

The driving force behind the growth of minority population is natural increase. Currently, there are 


\section{FIGURE 1. U.S. POPULATION PROJECTIONS BY RACE AND HISPANIC ORIGIN, 2015 AND 2060}

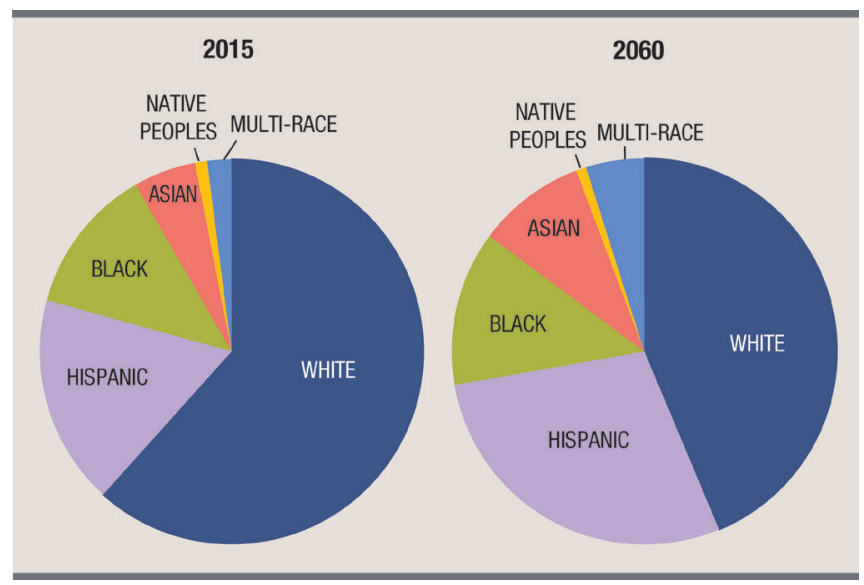

Source: U.S. Census Bureau Population Projections 2014

3.8 minority births for every death, among Hispanics the ratio is even higher at 6.7 births per death. Such high birth to death ratios produce substantial population increase. In contrast, the ratio of births to deaths is currently less than 1 among non-Hispanic whites according to Census Bureau estimates. There are many more births than deaths among minorities because this population is on average more than ten years younger than the non-Hispanic white population. This results in more women of childbearing age and fewer older adults at high risk of mortality.

Natural increase is projected to account for more than two-thirds of future minority population increase, except among Asians. This is consistent with current trends. Between 2010 and 2013, 69 percent of the minority population increase came from natural increase. Among Hispanics, it accounted for 78 percent of the population gain. Thus, while natural increase is now minimal among non-Hispanic whites and is projected to fall, it is expected to produce most of the minority population increase that will fuel future U.S. population growth.

The projected growth of the minority population combined with stagnation and eventual non-Hispanic white population decline will continue to increase the diversity of the population. Minorities currently represent 37 percent of the U.S. population. By 2045, no group will constitute a majority of the U.S. population, and nonHispanic whites are projected to represent just 44 percent of the population in 2060.

Children are in the vanguard of this growing diversity. Last year, nearly 50 percent of the babies born in the United States were minority according to Census Bureau estimates. Though diversity is greatest among infants, nearly 47 percent of those under age 20 are minority.
In contrast, 79 percent of the population over 65 is non-Hispanic white; projections suggest that whites will constitute the vast majority of the older population for the foreseeable future. Growing child diversity is fueled both by more minority children and by fewer non-Hispanic white children. Between 2000 and 2012, the minority child population grew by 25 percent, while the non-Hispanic white child population diminished by nearly 12 percent.

These changes reflect the differential impact of population aging on the population of women of childbearing age. There are 9 percent fewer white women of prime childbearing age now than in 2000, while there are 25 percent more minority women in this age group. This change, coupled with higher fertility rates among some minority groups, have made children the leading edge of an increasingly diverse society. Though the Great Recession has slowed both the number of births and fertility rates among young women, the new Census Bureau projections suggest that the U.S. population will continue to grow and become more diverse, albeit at a somewhat slower pace than previously projected.

\section{Data}

This analysis is based on Census Bureau projections and population estimates. Population projections are made using the best data available but necessarily involve estimates of future fertility, mortality, and migration that are highly sensitive to changing economic and social conditions. Thus, projections should be taken as suggestive of future demographic trends rather than as definitive. It is important to recognize that the classification of births by race in Census Bureau estimates differ from the procedures used by the National Center for Health Statistics (NCHS). Thus, there are differences in the number of births classified as non-Hispanic white by the two agencies. NCHS data does not allow for multiple race babiesall babies are classified to one race category. Census allows two or more race babies. NCHS data consistently show more non-Hispanic white births than Census data. Thus, readers should exercise caution in the interpretation of these results and recognize that this analysis is indicative of current trends using the best data available at this time.

\section{About the Author}

Kenneth M. Johnson is senior demographer at the Carsey School of Public Policy and professor of sociology at the University of New Hampshire (ken.johnson@unh.edu). 